\title{
Prevalence of social phobia among high school students in Erbil, Kurdistan region
}

\section{Abdulqader Hussein Hamad Gardi *}

\section{Abstract}

Background and objective: Kurdistan represents a model of the challenging mental health needs of adolescents in conflict-affected, low-income countries. Long-term instability, post-traumatic stress disorder, violent conflict, and wars undermine health and mental health status of people in Kurdistan, particularly children, who form half its population. This study aimed to determine the prevalence of social phobia among high school student in secondary schools.

Methods: A cross-sectional study was carried out during the period from January $2^{\text {nd }}$ to June $30^{\text {th }}$, 2014. Study participants were 1000 students recruited from 7 preparatory schools.

Results: The social phobia inventory (SPIN) revealed that $31.25 \%$ of the study sample showed symptoms of social phobia. There were no differences of social phobia among the ages of students. The rate of social phobia was higher in males than females with the mean score of 33.67 and 30.52 , respectively.

Conclusion: The findings of the study refer that most of the students in the preparatory school indicate symptoms of social phobia.

Keywords: Prevalence; Social phobia; Schools; Students.

\section{Introduction}

Social phobia is defined by diagnostic and statistical manual 5 (DSM-V) as an anxiety disorder characterized by a persistent fear of one or more social or performance situations in which the person is exposed to unfamiliar people or possible scrutiny by others. Social phobia, which is also known as social anxiety disorders, the onset of social phobia almost always occurs in childhood or the mid teens; onset after the age 25 is unusual. The disorder is often a lifelong problem, although its severity may diminish in adult life. Adults and adolescents with social phobia, as well as many children with the disorder, have sufficient insight to recognize that their fears are excessive and unwanted. This factor often adds to their distress and feelings of inferiority. ${ }^{1} \quad A$ high school student who refuses to go for classes because she/he is afraid that her/his teachers would make her/his talk in front of their peers; a woman who complains from marketing because she believes that all people are watching her; and a young man who fears from meetings people because someone may ask him a question - these cases have social phobia, also known as social anxiety disorder. Social phobia is characterized by an intense fear of situations, usually social or performance situations where embarrassment may occur. ${ }^{2}$ The prevalence of social phobia is, in fact, difficult to grasp. Socialization is largely culture bound and what one considers 'odd' maybe a part of another culture's socializing standards. Also, people with social phobias tend to ignore their conditions or learn to live with it. All in all, researchers believe that there are many out there with social phobias of varying level of ability. In the United States, an estimated $2 \%$ to $7 \%$ of people are said to have suffered from some social phobia during their lifetimes. ${ }^{3}$ A large

* Department of Nursing, College of Nursing, Hawler Medical University, Erbil, Iraq. 
number of studies provide evidence for the presence of social phobia in adolescence and then to adulthood ${ }^{4}$. In the study of Pine (1998) prevalence rates for girls range from $10.1 \%$ to $12.5 \%$ and for the boys, the rate of phobia prevalence is from $6.7 \%$ to $6.8 \%$ which declines over the years ${ }^{5}$. According to Breton, Bergeron, in Quebec social phobia Survey, the rate of phobia is more in boys than in girls between 15-20 years of age. ${ }^{6}$ A study reported that the prevalence of social phobia among girls is higher (approximately 33\%) than that in boys (approximately 20\%). ${ }^{7}$ Another study reported social phobia in girls more than those in boys. ${ }^{8}$ Social phobia varies from adolescence to others. Symptoms include excessive fears and worries, feelings of inner restlessness, and a tendency to be excessively wary and vigilant. Even in the absence of an actual threat, some teenagers describe feelings of continual nervousness, restlessness, or extreme stress. In a social setting, anxious teenagers may appear dependent, withdrawn, or uneasy. They seem either overly restrained or too emotional. They may be preoccupied with worries about losing control or unrealistic concerns about social competence. $^{8}$ This study aimed to determine the prevalence of social phobia among high school student in Erbil city, Kurdistan region.

\section{Methods}

Research design: A cross-sectional study was conducted in seven preparatory schools in Erbil city during the period of January $2^{\text {nd }}$ to June $30^{\text {th }}, 2014$.

Study sample: Participants in the study were 1000 adolescents, aged 15-20 years. Adolescents were students studying in class 10th and Class 11th standard. Participants were selected two stages using convenience sampling technique such that the final sample was drawn from seven schools, according to their situations in Erbil city.

A pilot study was carried out on thirty students to determine the reliability of the questionnaire. The pilot study samples were selected from the same schools. After two weeks the same sample was selected to ask the same items in the questionnaire.

Reliability of the questionnaire: The reliability coefficient of the test was measured via test-retest method on a sample of 30 male and female Kurdish students. The analysis of the data revealed a reliability coefficient of $0.89(P=0.01)$, which was statistically adequate.

Ethical considerations: before collecting the data, the researchers obtained approval of the Ethics Committee at the College of Nursing, Hawler Medical University. The official permission from the Erbil General Directorate of Education and the schools' management in Erbil city was obtained.

\section{Design of questionnaire:}

Part I: Sociodemographic data includes the general information about students such as age, sex, marital status, economic level, religion and nationality and the name of the school.

Part II: Social Phobia Inventory (SPIN) scale contains seventeen items. Add the score from each item to produce a total score. Higher scores indicate more severe symptoms.

Data collection: Social Phobia Inventory and a demographic-social questionnaire were used for data collection. The original data were collected from among 1000 students selected from seven schools. Test of social phobia was assessed through a translated version of social phobia Inventory to the Kurdish language forward and backward. The form distributed to the students in the classroom and refilled by them, and form collected by the researcher in some schools or by teachers in other schools. The subjects are instructed to respond according to how they feel by reporting the frequency with which they have experienced. The responses to the items of test social phobia questionnaire comprise the five-point scales in-cluding 1 ) None; 2) Mild; 3) Moderate; 4) severe; 5) very severe The mean score for the 
seventeen items (total score) was determined. This test does not have any diagnostic cut-off point, and the results should be interpreted through comparison. Assistance could be taken during the procedure. The informed consent was taken from the principal of the school. Any student who faced any difficulty in filling up the form was helped and encouraged to fill the complete form. The form was collected from the students after 25 minutes. Incomplete form, if received, the student was encouraged to complete it, and otherwise, the form was discarded and not included.

Data management and statistical analysis: the data were analyzed through the statistical package for the social sciences (version 18). Descriptive data analysis included calculation of frequencies, percentages, means and standard deviations. Inferential statistical data analysis included One-Way Analysis of Variance to test the equality means. Also recall that the $F$ test statistic is the ratio of samples variances.

\section{Results}

We recruited 1000 students from the identified classrooms in seven schools. Out of these 1000 students, 95 (9.5\%), 207 $(20.7 \%), \quad 135$ (13.5\%), 78 (7.8\%),152 (15.2), 142 (14.2) and 191 (19.1) were from Chinar, Nanakaly, Media, Barzani Namir, Rizgari, Hawlery Kchan and Shamy Kchan schools, respectively. Students from two stages were included in the study; $55.7 \%$ from the $10^{\text {th }}$ class and $44.3 \%$ from the $11^{\text {th }}$ class. Most students were from the scientific branch $(80.8 \%)$ while $19.2 \%$ were from the literary branch (Table 1).

Table 1: The schools' distribution and the number of students.

\begin{tabular}{lcc}
\hline Variable & Frequency & Percent \\
School & 95 & 9.5 \\
\hline Chinar & 207 & 20.7 \\
Nanakaly & 135 & 13.5 \\
Media & 78 & 7.8 \\
Barzaninamir & 152 & 15.2 \\
Rizgarikuran & 142 & 14.2 \\
Hawlerykchan & 191 & 19.1 \\
ShamyKchan & & \\
Stages & 557 & 55.7 \\
10 & 443 & 44.3 \\
11 & & \\
Part & 808 & 80.8 \\
Science & 192 & 19.2 \\
Literary & 1000 & 100.0 \\
Total & 1499 & \\
\hline \hline
\end{tabular}


The participants comprised 770 females $(77.0 \%)$ and 230 males $(23.0 \%)$. Their ages fell into 6 category; 15 years $(16.2 \%)$, 16 years $(37.7 \%), 17$ years $(28.1 \%), 18$ years $(13.0 \%), 19$ years $(3.4 \%)$ and 20 years $(1.6 \%)$. Regarding marital status 92.9 were single, and 7.1 were married. Regarding the answer to the students as bad, median and good, economic status only $0.9 \%$ were bad, $29.6 \%$ were median and 69.5 were good. Most students
$(97.8 \%)$ were living inside the city and $2.2 \%$ were living outside the city. Most of them were Muslim (99.8\%) and Kurdish (99.6\%) as shown in Table 2. Table 3 shows the degree of social phobia among high school students, $16.7 \%$ of the students were normal, $29.7 \%$ had a mild social phobia, $34.3 \%$ had a moderate social phobia, $14.8 \%$ had a severe social phobia and $4.5 \%$ had a very severe social phobia.

Table 2: The subjects' socio-demographic characteristics.

\begin{tabular}{|c|c|c|}
\hline Characteristics & n. & $\%$ \\
\hline \multicolumn{3}{|l|}{ Age (years) } \\
\hline 15 & 162 & 16.2 \\
\hline 16 & 377 & 37.7 \\
\hline 17 & 281 & 28.1 \\
\hline 18 & 130 & 13.0 \\
\hline 19 & 34 & 3.4 \\
\hline 20 & 16 & 1.6 \\
\hline \multicolumn{3}{|l|}{ Gender } \\
\hline Male & 230 & 23.0 \\
\hline Female & 770 & 77.0 \\
\hline \multicolumn{3}{|l|}{ Marital Status } \\
\hline Single & 929 & 92.9 \\
\hline Married & 71 & 7.1 \\
\hline \multicolumn{3}{|c|}{ Socioeconomic status } \\
\hline Good & 695 & 69.5 \\
\hline Median & 296 & 29.6 \\
\hline Bad & 9 & .9 \\
\hline \multicolumn{3}{|l|}{ Residence } \\
\hline inside city & 978 & 97.8 \\
\hline out side & 22 & 2.2 \\
\hline \multicolumn{3}{|l|}{ Religion } \\
\hline Muslim & 998 & 99.8 \\
\hline Christian & 1 & .1 \\
\hline Others & 1 & .1 \\
\hline \multicolumn{3}{|l|}{ Nationality } \\
\hline Kurd & 996 & 99.6 \\
\hline Arab & 2 & .2 \\
\hline Others & 2 & .2 \\
\hline Total & 1000 & 100.0 \\
\hline
\end{tabular}

Table 3: The degree of social phobia among studied students.

\begin{tabular}{lcc}
\hline Phobia & Frequency & Percent \\
\hline No social phobic & 167 & 16.7 \\
Mild & 297 & 29.7 \\
Moderate & 343 & 34.3 \\
Severe & 148 & 14.8 \\
Very Severe & 45 & 4.5 \\
Total & 1000 & 100.0 \\
\hline \hline
\end{tabular}


Table 4 reveals that there was no significant difference between the $10^{\text {th }}$ and $11^{\text {th }}$ classes of study $(P=0.303)$ and the scientific and literary branch of the students $(P=0.878)$. There was also no significant association between the residence inside and outside of the city $(P=0.462)$, but there was a significant association between male and female students $(P<0.001)$ and single and married students $(P=0.036)$.

Table 4: Socio-demographic differences.

\begin{tabular}{|c|c|c|c|c|c|c|c|}
\hline & & $\mathbf{N}$ & Mean & Std. Deviation & $\mathbf{T}$ & df & $P$ value \\
\hline \multirow[t]{3}{*}{ Stage } & $10^{\text {th }}$ class & 557 & 30.92 & 11.432 & & & \\
\hline & & & & & -1.031 & 998 & 0.303 \\
\hline & $11^{\text {th }}$ class & 443 & 31.65 & 10.480 & & & \\
\hline \multirow[t]{3}{*}{ Branch } & Science & 808 & 31.27 & 11.206 & & & \\
\hline & & & & & 0.153 & 998 & 0.878 \\
\hline & Literary & 192 & 31.14 & 10.229 & & & \\
\hline \multirow[t]{3}{*}{ Gender } & Male & 230 & 33.67 & 9.021 & & & \\
\hline & & & & & 3.835 & 998 & 0.000 \\
\hline & Female & 770 & 30.52 & 11.457 & & & \\
\hline \multirow[t]{3}{*}{$\begin{array}{l}\text { Marital } \\
\text { status }\end{array}$} & Single & 929 & 31.04 & 10.893 & & & \\
\hline & & & & & -2.100 & 998 & 0.036 \\
\hline & Married & 71 & 33.89 & 12.360 & & & \\
\hline \multicolumn{8}{|c|}{ Incidence } \\
\hline & Inside city & 978 & 31.21 & 11.071 & & & \\
\hline & & & & & -0.736 & 998 & 0.462 \\
\hline & Out side & 22 & 32.95 & 8.482 & & & \\
\hline
\end{tabular}


Table 5 shows that there was a significant levels of economic status $(P<0.001)$, and difference between the whole students in a non-significant difference between the seven schools $(P<0.001)$, in addition, there was a significant difference between the ages of the student $(P=0.841)$.

Table 5: The severity of social phobia among the students in each school.

\begin{tabular}{lccccc}
\hline School & N & Mean & $\begin{array}{c}\text { Std. } \\
\text { Deviation }\end{array}$ & F-test One-way-ANOVA & P value \\
\hline Chinar & 95 & 25.32 & 11.616 & & \\
Nanakaly & 207 & 32.97 & 9.619 & & \\
Media & 135 & 23.13 & 9.778 & & \\
Barzaninamir & 78 & 33.92 & 6.909 & 24.985 & \\
Rizgarikuran & 152 & 33.55 & 9.951 & & \\
Hawlerykchan & 142 & 33.85 & 11.176 & & \\
ShamyKchan & 191 & 33.20 & 11.383 & & \\
Total & 1000 & 31.25 & 11.021 & & \\
\hline
\end{tabular}

Table 6: Association between the age of studied students and the level of social phobia.

\begin{tabular}{lccccc}
\hline Age & $\mathbf{N}$ & Mean & $\begin{array}{c}\text { Std. } \\
\text { Deviation }\end{array}$ & F-test One-way-ANOVA & $\boldsymbol{P}$ value \\
\hline 15 & 162 & 30.75 & 11.225 & & \\
16 & 377 & 31.08 & 11.109 & & \\
17 & 281 & 31.21 & 10.971 & & \\
18 & 130 & 31.90 & 11.244 & 0.412 & \\
19 & 34 & 31.85 & 10.037 & & \\
20 & 16 & 34.13 & 8.397 & & \\
Total & 1000 & 31.25 & 11.021 & & \\
\hline
\end{tabular}

Table 7: Phobia Scores of the Students from Different Socio-economic background.

\begin{tabular}{lccccc}
\hline $\begin{array}{l}\text { Economical } \\
\text { Status }\end{array}$ & N & Mean & $\begin{array}{c}\text { Std. } \\
\text { Deviation }\end{array}$ & F-test One-way-ANOVA & $\boldsymbol{P}$ value \\
\hline Good & 695 & 30.33 & 11.130 & & \\
Median & 296 & 33.19 & 10.213 & 8.855 & $<0.001$ \\
Bad & 9 & 38.00 & 17.571 & & \\
Total & 1000 & 31.25 & 11.021 & & \\
\hline \hline
\end{tabular}




\section{Discussion}

In this study, we investigated the prevalence of social phobia among high school students in different schools in Erbil city. Recent research on social phobia shows a high prevalence of social phobia among students. This study measured adolescent social phobia across a number of dimensions the SPIN is a 17-item self-rating scale for social anxiety disorder (social phobia). The mean of social phobia score for adolescent boys (33.67) was found to be slightly higher than that for adolescent girls (30.52). These findings conflicts with previous research regarding adolescent anxiety in developed countries wherein girls are more likely to develop anxiety symptoms and disorders. ${ }^{9,10}$ This difference may be attributed to cultural practices in Kurdish society. Despite the context of domestic change brought about by globalization, underlying patriarchal structures persist ${ }^{11}$ wherein boys continue to face more pressure regarding their proper choice of vocation and future career. ${ }^{12}$ However, at the same time, it is relevant to highlight that the difference between the mean of social phobia scores of boys and girls, although statistically significant, is not contextually substantial. Phobias levels of the adolescent girls, therefore, cannot be dismissed simply because the levels are, on average, lower than those for the adolescent boys ${ }^{13}$ Families have differential expectations about the likely outcomes of education for boys and girls toward fear especially in Kurdistan. Investment in schooling for daughters is seen primarily as a route to attaining better marriage prospects. ${ }^{14}$ Investment in sons' education, however, is related to the expectation that their future employment will provide familial security. The weight of this responsibility falls heavily on boys. This is particularly problematic in Kurdistan as unemployment and underemployment remain high for both men and women. Our findings in this study are not similar to that of other reports in the literature ${ }^{15,16}$ showing that the anxiety level of girls is invariably higher than that of the boys. However, this difference is also seen in some investigations. Possible explanation is that males are more defensive about admitting anxiety because it might be seen as threatening to their masculinity; they are trained to cope with anxiety by denying it or by finding ways to overcome it. ${ }^{17}$ Females are encouraged to admit to anxiety, which is perceived as a feminine trait, and the male has more responsibility to life and family care in Kurdistan Region. The mean value for social phobia was found to be highest for the students belonging to the bad and (38.00) medium socio-economic class (33.19), followed by the students belonging to the lower class (30.33). This finding is not surprising in light of the above discussion about the relationships between the rising middle class, the demand for educational achievement and drive for occupational prestige. Increases in secondary enrollment rates in Kurdistan reflect emerging middle-class parental desires and expectations. In Kurdistan economic and social development itself is under great pressure of Iraqi blockade and this is keenly felt by the middle class who are under greater stress to hold their ground, protect their social position and to move ahead. ${ }^{18}$ The pressure on the lower classes is perhaps better understood from a psychological perspective, for example, in a review of studies from low and middle-income countries ${ }^{19}$ confirmed the association (albeit weak) between indicators of poverty and the risk of common mental disorders. Importantly, exploration of the mechanism of the relationship revealed specific factors such as the experience of insecurity, hopelessness, rapid social change, violence and physical ill-health explained heightened risk. ${ }^{20}$ The least anxiety is seen in the case of the high socio-economic adolescents, this may be partly attributed to their secured future at least regarding material and financial aspects, as reported, and the prevalence of anxiety disorders 
tends to decrease with higher socioeconomic status. ${ }^{21}$ Regarding the age of students, there are no significant differences between the age of the student and the level of social phobia that is related to the age of adolescence 15-20 years. There are no significant differences between the $10^{\text {th }}$ and $11^{\text {th }}$ stages also between the literacy and science branch. Besides there are no significant differences between married and single student that is related to same care presents before and after marriage among their parents. There are no differences between the level of social phobia and their incidence because after destroying four thousand and five hundred villages in Kurdistan most of the adolescence lived in the cities.

\section{Conclusion}

The incidence of social phobia in Government school was $34.3 \%$. Males showed a higher incidence of social phobia 33.67 when compared to females 30.52 , and there are no differences in the level of social phobia regarding the ages, marital status, incidence, branches and $10^{\text {th }}$ and $11^{\text {th }}$ classes of students. There are significant differences between the level of social phobia with gender and economic status of the studied students.

\section{Conflicts of interest}

The author reports no conflicts of interest.

\section{References}

1. Gauer G, Picon P, Vasconcellos S, Turner S, Beidel D. Validation of the Social Phobia and Anxiety Inventory for Children (SPAI-C) in a sample of Brazilian children. Brazilian J Med Biol Res 2005;38(5):795-800.

2. Sadock BJ. Kaplan \& Sadock's comprehensive textbook of psychiatry: lippincott Williams \& wilkins Philadelphia, PA; 2000.

3. Hitchcock CA, Chavira DA, Stein MB. Recent findings in social phobia among children and adolescents. Isr J Psychiatry Relat Sci 2009;46 (1):34.

4. Costello EJ, Compton SN, Keeler G, Angold A. Relationships between poverty and psychopathology: A natural experiment. JAMA 2003; 290 (15):2023-9.

5. Inam A, Mahjabeen A, Abiodullah M. Prevalence of Social Anxiety among Elementary Grade
Children. Bull Edu Research. 2012;34(1).

6. Breton J-J, Bergeron L, Valla J-P, Berthiaume C, Gaudet N, Lambert J et al. Quebec child mental health survey: prevalence of DSM-III-R mental health disorders. J Child Psychol Psychiatry1999; 40 (03):375-84.

7. Fergusson DM, Horwood LJ, Lynskey MT. Prevalence and comorbidity of DSM-III-R diagnoses in a birth cohort of 15 year olds. J Am Acad Child Adolsc Psychiatry 1993; 32 (6):1127-34.

8. Essau CA, Conradt J, Petermann F. Frequency and comorbidity of social phobia and social fears in adolescents. Behav Res Ther 1999;37(9): 831-43.

9. Beesdo K, Knappe S, Pine DS. Anxiety and anxiety disorders in children and adolescents: developmental issues and implications for DSM-V. Psychiatric Clinics of North America 2009; 32(3):483-524.

10. Poulton R, Milne BJ, Craske MG, Menzies RG. A longitudinal study of the etiology of separation anxiety. Behav Res Ther 2001; 39 (12):1395-410.

11. Campbell MA, Rapee RM. The nature of feared outcome representations in children. J Abnorm Child Psychol 1994;22(1):99-111.

12. Costello EJ, Mustillo S, Erkanli A, Keeler G, Angold A. Prevalence and development of psychiatric disorders in childhood and adolescence. Arch Gen psychiatry 2003;60(8):837-44.

13. Deb $S$, Chatterjee $P$. Styles of parenting adolescents: the Indian scenario: Akansha Publishing House; 2008.

14. Weiss DD, Last CG. Developmental variations in the prevalence and manifestation of anxiety disorders. The developmental psychopathology of anxiety2001;1:27-42.

15. Mehregan F, Najjarian B, Ahmadi A. The relation between test anxiety and performance among Ahvaz university students. Ferdowsi J Psychol 2001;2:7-24.

16. Mehrabizadeh M, Aboulghasemi A, Najjarian B. The prevalence of test anxiety and the relation between it and self-efficacy and locus of control. Ahwaz J Psychol 2000;1:55-72.

17. Mwamwenda TS. Gender differences in test anxiety among South African University students. Percept Mot Skills 1993;76(2):554-.

18. Ganguly-Scrase R, Scrase TJ. Globalisation and the middle classes in India: The social and cultural impact of neoliberal reforms: Routledge; 2008.

19. Patel V, Kleinman A. Poverty and common mental disorders in developing countries. Bulletin WHO 2003;81(8):609-15.

20. Sadock BJ, Sadock VA. Kaplan and Sadock's synopsis of psychiatry: Behavioral sciences/ clinical psychiatry: Lippincott Williams \& Wilkins; 2011.

21. Sadock BJ. Kaplan \& Sadock's comprehensive textbook of psychiatry: lippincott Williams \& wilkins Philadelphia, PA; 2000. 